\title{
The influence of harmonics from non-linear loads in the measuring transformers of electrical substations
}

\author{
Oscar Armando Maldonado Astorga, José Luz Silveira, Julio Carlos Damato \\ Laboratory of High Voltage and Electric Power Quality \\ (Laboratório de Alta Tensão e Qualidade de Energia - DEE) \\ Otimization Group of Energy Systems \\ (Grupo de Otimização de Sistemas Energéticos) \\ São Paulo State University - unesp - Campus de Guaratinguetá \\ www.feg.unesp.br/gose \\ oscarama@feg.unesp.br, joseluz@ feg.unesp.br, jdamato@feg.unesp.br
}

Keywords: Substation, Measuring, Power Quality, Harmonics, Non-linear loads

Abstract: The mainstreams of research papers developed to analysis of electrical systems power quality for non-linear loads are conducted for low voltage feed. This, if in one hand have furnished important results about the performance of power quality provide by installation, in other hand drops off bad quality effects of electrical energy in high and medium voltage distribution net, mainly in effects of harmonics components, in principals apparatus in substations entrance, notably in current and voltage transformers employed to feed protection and measuring systems of installation.

This paper explains conclusions of a comparative analysis of voltage and currents behavior and harmonics components between voltage in secondary feed side and primary feed side of a medium voltage substation. In this way, the objective of research is contributed to a better understanding of measurement transformers behavior and his influence in measuring, protection and control, when installed in equipment with predominance of non-linear loads.

The objective of paper is identifying the error that can be present in electrical parameters of substation, when measuring in medium or high voltage are used. With this proposal was building an experimental substation in Power Quality Laboratory of Sao Paulo State University. The installation is composite by 2 distribution transformers, $30 \mathrm{kVA}, 13,800$ / $220 \mathrm{~V}$, connect in substation entry and other in outlet. Between transformers exist 3 current transformers and 2 voltage transformers and also surge arresters and monophase disconnectors. The load was welding machines, resistors and gas discharge high pressure sodium lamps, used in public illumination and industrial installations.

The results demonstrate that exist an intense influence of non-linear loads in medium voltage when measuring with current or voltage transformers.

\section{Introduction}

The predominance and constant increase of non-linear loads in electric system and its influence in Power Quality, is being object of studies and publications, because of problems introduction in electric system that still not yet totally known [1], [2], [3]. Most of these studies seeks electric system behavior under point of view of Power Quality, in feeding side, in low voltage once it is more accessible [4], [5]. The interest of this work is study the influence of the harmonics components in the measuring transformer and therefore to identify, and if possible, to quantify, the mistake that can be introduced in readings of electric greatness in medium or high voltage substations with these components harmonic presence originated by non-linear loads.

With this purpose, the assembly of an experimental substation was accomplished in Laboratory of High Voltage and Electric Power Quality of São Paulo State University unesp, Guaratinguetá Campus.

Using this substation, several rehearsals were accomplished with several configurations of loads that represent a small typical industrial installation.

During accomplishment of rehearsals, was made voltage and currents registrations, as well as found harmonic composition, so much low voltage side of 220 Volts in distribution transformer secondary that feeds several load configurations. Also was made voltage and currents registry and harmonic composition supplied by substation potential and current transformers, in medium voltage side, 13,800 Volts.

The observations and conclusions presented were obtained from comparison and analysis of results. 


\section{Experimental substation}

For accomplishment of this work it was developed and implanted, an experimental substation in Laboratory of High Voltage and Electric Power Quality of unesp, Guaratinguetá Campus, composed by 2 transformers of $13.8 \mathrm{kV} / 220 \mathrm{~V}, 30 \mathrm{kVA}$, linked one in substation entry and other in outlet. Between the 2 transformers, 3 monophase disconnectors droughts are installed, 3 surge arresters, 3 current transformers (CT), accurately for measurement, of 0.3 for load of up to $25 \mathrm{VA}$ and for protection of $10 \mathrm{~B}$. Also, 2 potential transformers (PT) accurately of $0.3 \%$ for measurement with load of $75 \mathrm{VA}$ and protection.

The loads, used in several configurations are constituted by high pressure sodium lamp of 3 types more used in facilities industrial or public ilumination, that are: a $100 \mathrm{~W}$ lamp, type Sodium Gold light; a 150W lamp, type high pressure sodium and $250 \mathrm{~W}$ lamp, type V.S. Gold light, all made by Sylvania. They are also used, 2 weld electric machine with following characteristics: power of $6.5 \mathrm{~kW}$ each, continuous regime, feeding in $220 \mathrm{~V}$, exit $24 \mathrm{~V}$, maximum current $107 \mathrm{~A}$.

The existent linear loads in any installation are represented in this study, for 3 banks of resistances totaling a power of $12 \mathrm{~kW}$.

For obtaining of voltage and currents curves was used an oscilloscope Tektronix model THS720P.

The substation diagram is shown in Figure 1.

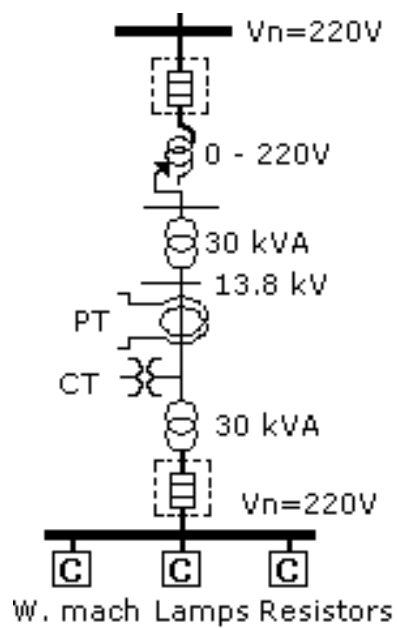

Figure 1: Unifilar diagram of Laboratory Electric Substation

\section{Used methodology}

The accomplishment of rehearsals was begun trying to separate in first place non-linear loads. That is, to accomplish analysis first only for illu- mination system constituted by discharge lamps, then, only with weld electric machines, to load and no load conditions, later to lift the resistors bank characteristic for later to go containing loads in different configurations. The rehearsals execution showed however that was impossible this approach once current demanded by lamps separately was so small and don't was registered with reliability by measurement system in substation measurement transformers.

In same way, in verification of load characteristics for 2 weld electric machines separately, their internals circuit compensator acts from to compensate voltage and current waves deformations observed when no load operation of machines. The Figures 2 to 5 shows voltage and current waveforms aspects for this two situations.

In Figure 2, is shown current in a weld electric machine, in no load situation. The RMS current in machine is $1.115 \mathrm{~A}$. The bars diagram for harmonic components, Figure 3 displays a Totally Harmonic Distortion (THD-F) of $35.8 \%$.

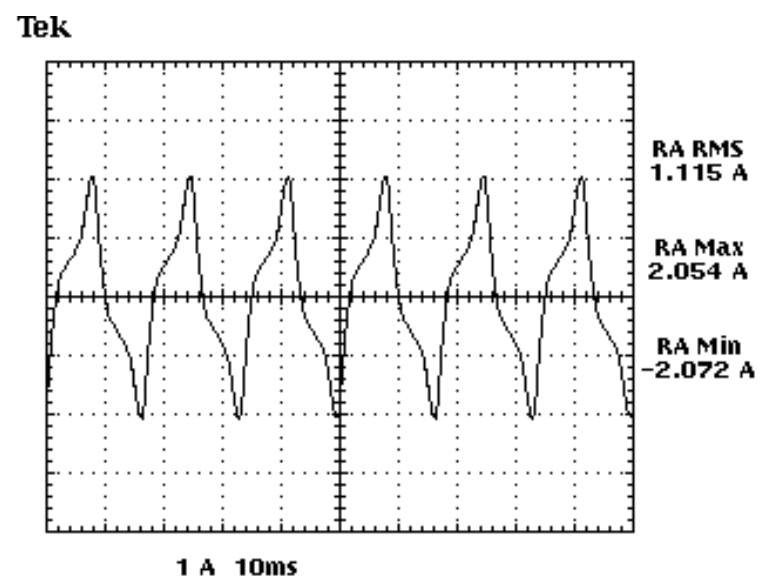

Figure 2: Current waveform for weld electric machine for no load situation.

In Figure 4 is shown current drain by a weld electric machine, in a load situation. The RMS current in machine is $35.56 \mathrm{~A}$, THD-F, shown in Figure 5 , is equal $6.2 \%$.

In Figure 2 and 4 is possible see the influence of internal compensatory circuit and weld electric machine filter.

Because of the fact that results, opted by to analyze a configuration composed by 3 loads types association, in way to guarantee that current values obtained starting from current transformer, submits a larger reliability than it allows results analysis. These results are not affected for this decision once analysis is comparative and used configuration in fact can characterize a real load configuration in small industrial workshops. 
Tek

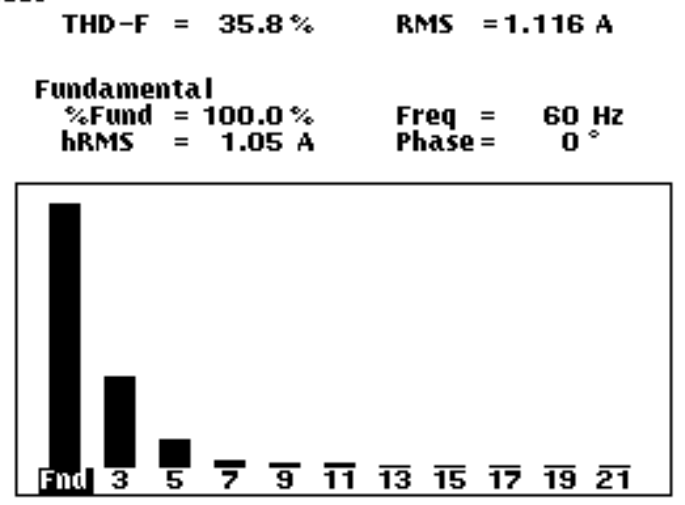

Figure 3: Current harmonic composition for weld electric machine without load.

Tek

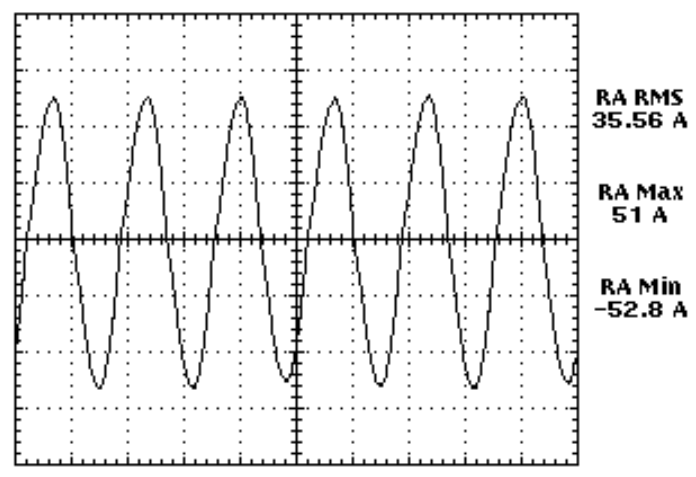

$20 \mathrm{~A} 10 \mathrm{~ms}$

Figure 4: Current waveform for weld electric machine with load.

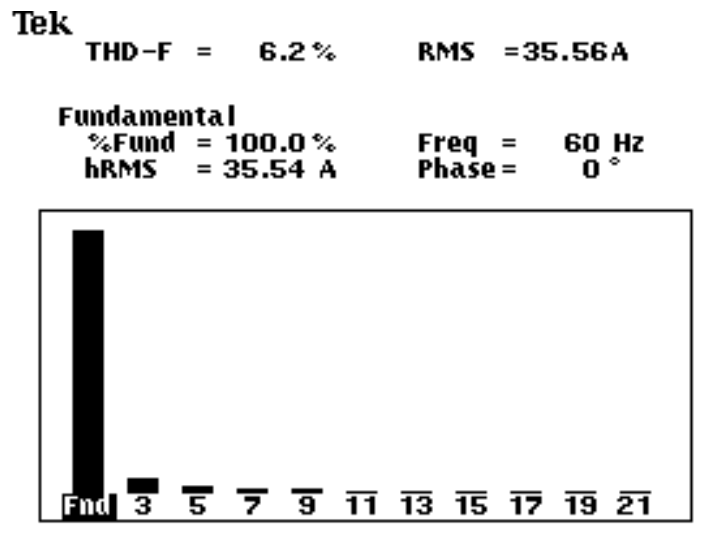

Figure 5: Current harmonic composition for weld electric machine with load.

\section{Experimental rehearsals accomplishment and obtained results}

The adopted load configuration is following: 2 weld electric machines feeded by 220 Volts among distribution transformer phases $\mathrm{A}$ and $\mathrm{C}, 3$ high pressure sodium lamps, also connected in phases $\mathrm{A}$ and $\mathrm{C}$, and 3 resistances banks connected in same phases.

The current distribution transformer oscilogram that feeds loads, for study configuration, is shown in Figure 6. In Figure 7, bars diagrams are shown for harmonics components presents.

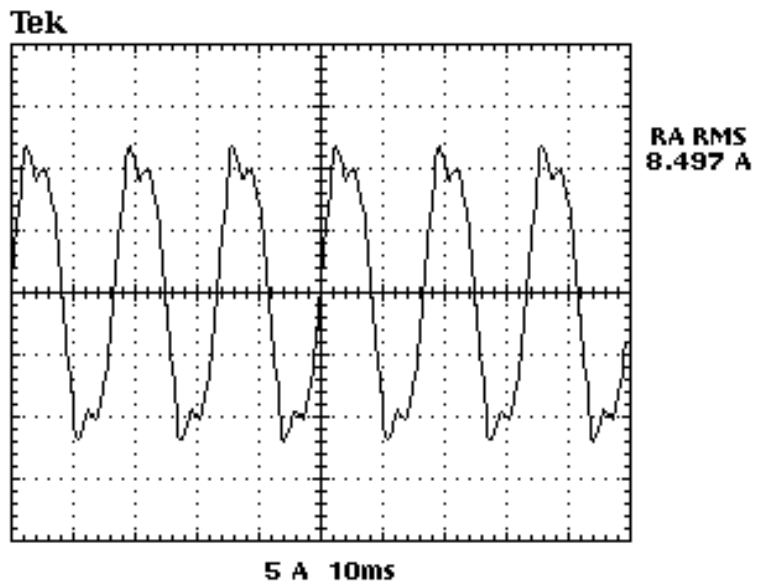

Figure 6: Load current waveform, for weld electric machine without load, lamps and resistances banks

It's observed in Figure 7, that THD-F in relation to fundamental is $15.9 \%$. The harmonic composition until order 9 component is shown in Table 1.

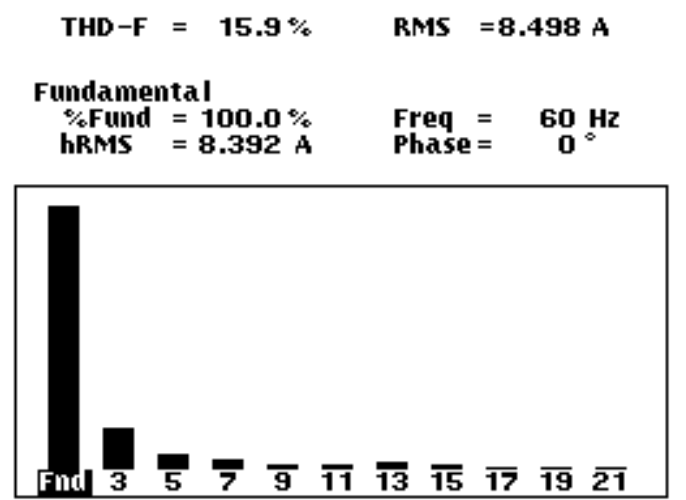

Figure 7: Current harmonic composition, for weld electric machine without load, lamps and resistors banks.

In Figure 8, current oscilogram for medium voltage side, for substation phase $A$, obtained from current transformer secondary is shows.

Can be observed in Figure 9 that THD-F is $19.3 \%$. The harmonics composition until order 9 component is shown in Table 1.

In Figure 10, substation phase B current oscilogram for medium voltage side, obtained from current transformer secondary is presented. 
It's observed in Figure 11, that THD-F is 24.7 $\%$. The harmonic composition until order $9 \mathrm{com}$ ponent is shown in Table 1.

\section{Tek}

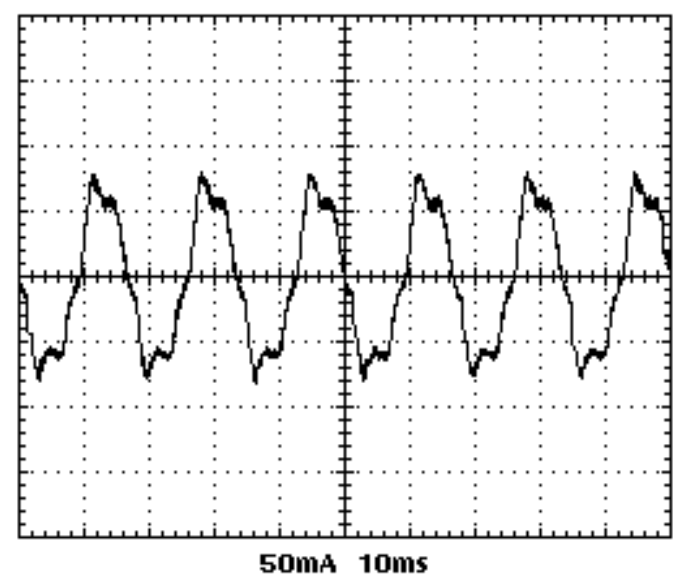

Figure 8: Current waveform, on medium voltage side, phase $A$

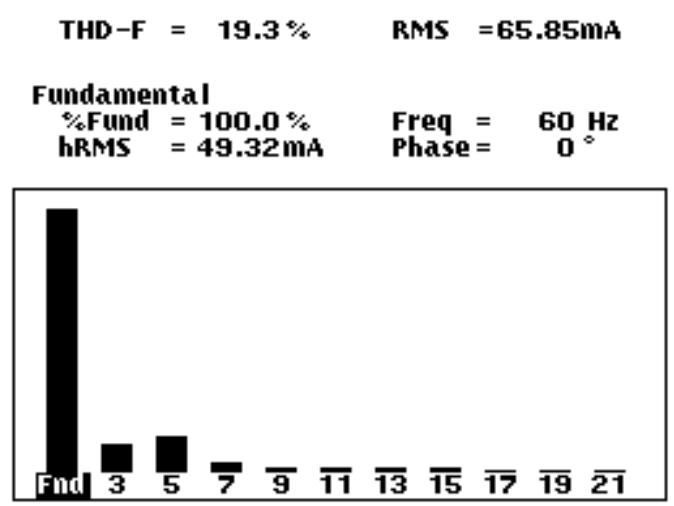

Figure 9: Current harmonic composition, on medium voltage side, phase $A$

Tek

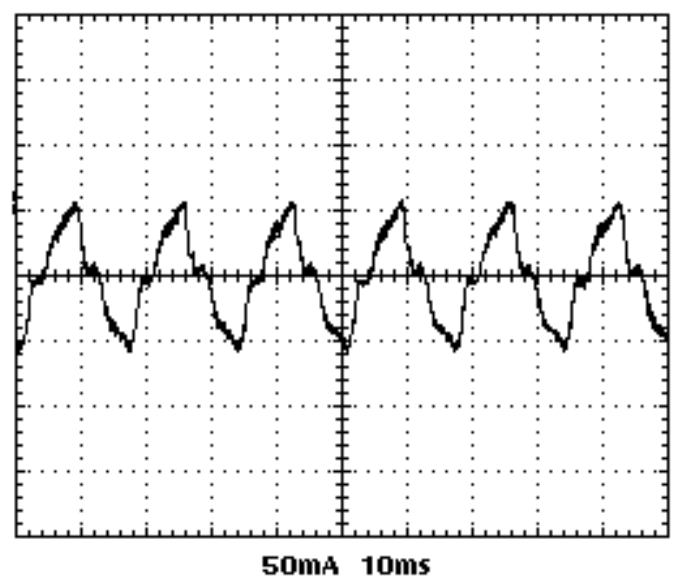

Figure 10: Current waveform, on medium voltage side, phase B

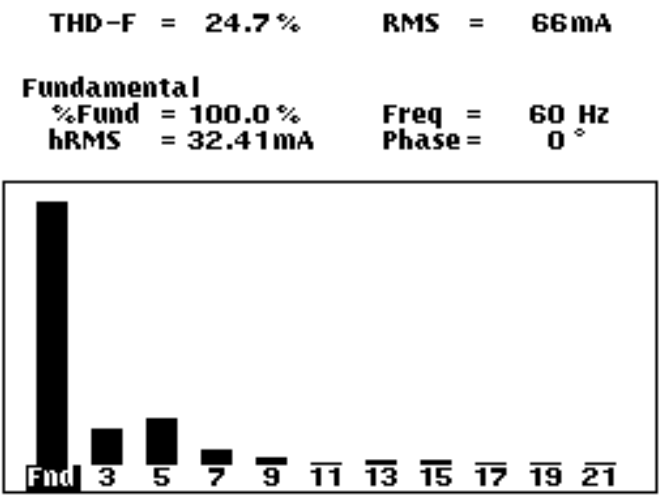

Figure 11: Current harmonic composition, on medium voltage side, phase $B$

In Figure 12, is submitted current oscilogram, medium voltage side, for substation phase $\mathrm{C}$, obtained in current transformer secondary.

Is observed in Figure 13 that THD-F is $24.7 \%$. The harmonic composition until order 9 component is shown in Table 1.

Table 1

Feeding current harmonics components in low voltage and medium voltage

\begin{tabular}{c|c|c|c|c}
\hline \multirow{2}{*}{ Order } & \multicolumn{4}{|c}{ Value \% } \\
\cline { 2 - 5 } & \multirow{2}{*}{$\begin{array}{c}\text { Low } \\
\text { voltage }\end{array}$} & \multicolumn{3}{|c}{ Medium voltage } \\
\cline { 3 - 5 } & & Phase A & Phase B & Phase C \\
\hline 3 & 14.6 & 10.4 & 13.5 & 10.7 \\
\hline 5 & 5.0 & 13.2 & 17.4 & 12.9 \\
\hline 7 & 3.0 & 3.1 & 5.4 & 5.2 \\
\hline 9 & 1.1 & 0.8 & 2.0 & 1.4 \\
\hline
\end{tabular}

\section{Results analysis}

The results shows, in first instance, that exists an influence of non-linear loads in measurements made in medium voltage side, through current transformers. This alteration shows for difference among values obtained between low voltage and medium voltage values, in what it's referred mainly to THD-F, and to harmonics components percentile values. In this analysis, only current components harmonics of each phase, until order ninth was considered. All value was showed in Table 1. 
Tek

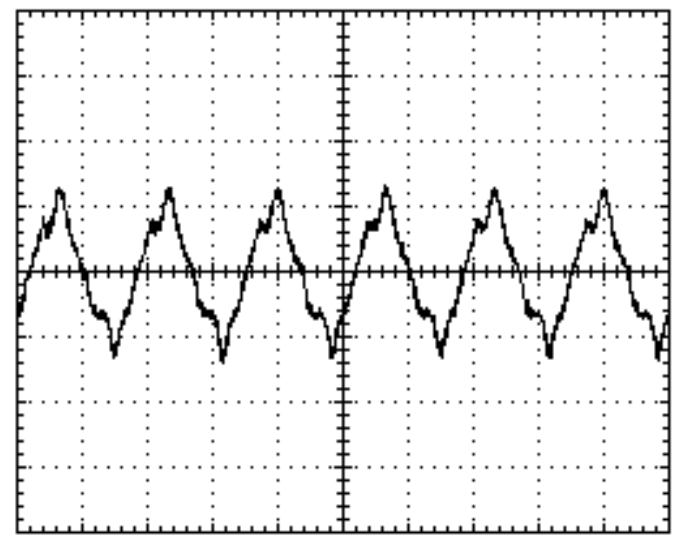

50ma 10ms

Figure 12: Current waveform, medium voltage side, phase $\mathrm{C}$

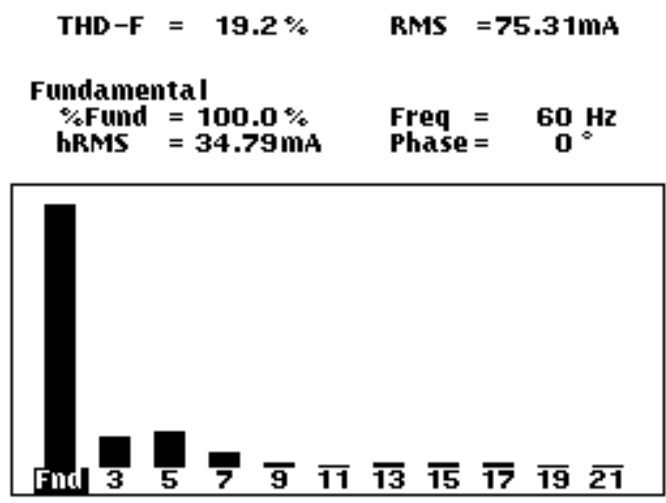

Figure 13: Current harmonics composition, medium voltage side, phase $\mathrm{C}$

In relation to values obtained in low voltage side, for THD-F in phase A, and those obtained in medium voltage side, is verified a variation of $17.6 \%$ among phases $\mathrm{A}$ and $\mathrm{C}$, and a difference of $35.6 \%$ in relation to phase $B$. A part of results is due without a doubt to load unbalance but it is an sign that careful should be been for not committing interpretation mistakes and evaluation in deciding time control qualify measures for an installation, based on measurement transformers data.

In the same way, in harmonics components relationship, is verified that difference among low and medium voltage values, come up to $28.7 \%$ for 3rd harmonics, $71.2 \%$ for 5 th, $44.4 \%$ for 7 th and $45 \%$ for order 9 th harmonics.

It's also evident, from results shows, that harmonics content evaluation in installations, to verify for instance the norms [6], [7], cannot so only based on results analysis obtained starting from measurement transformers.

Other observations in percentage of mistake introduced in readings or in obtained measure- ment transformers signs for control devices or protection performance, should be object of future continuation of this work.

\section{Currents in entry transformer}

In Figure 1, is showed in bottom of figure the entrance $30 \mathrm{kVA}$ transformer, used like the feed for experimental substation. The current in each phase in this transformer is showed in Figure 14, 15 and 16. The respective THD is showed in Table 2 .

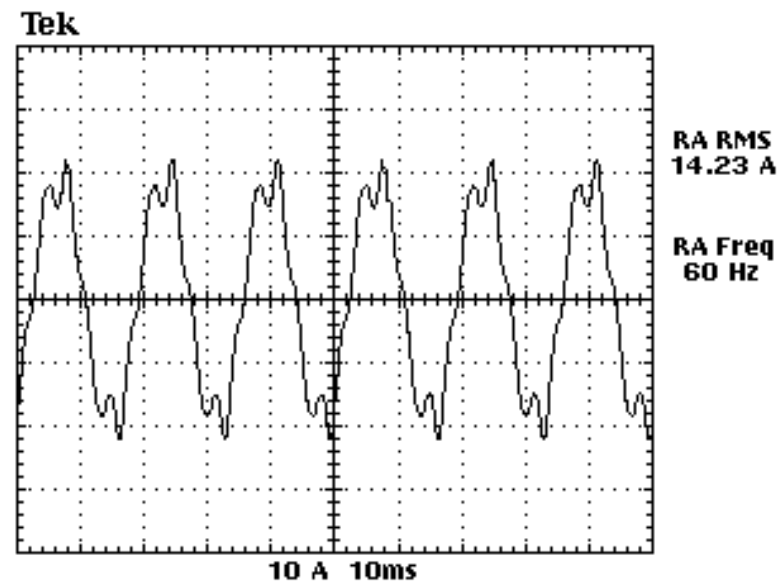

Figure 14: Current in entry transformer, phase A

Tek

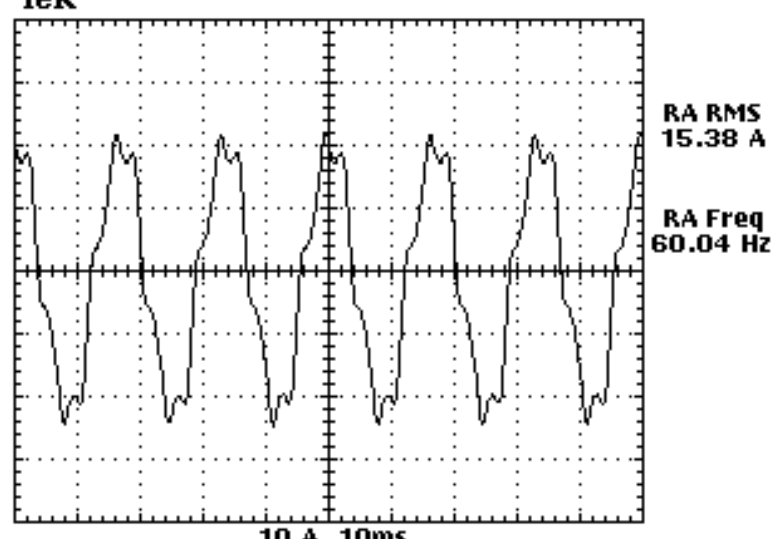

Figure 15: Current in entry transformer, phase B

Tek

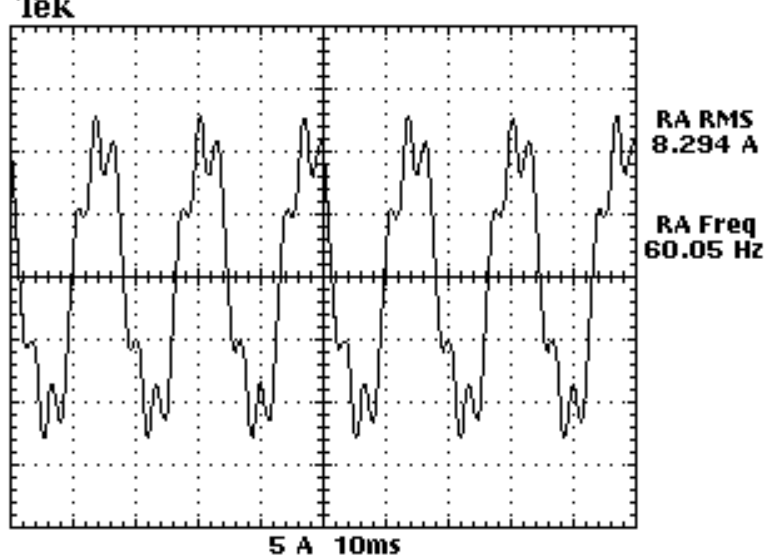

Figure 16: Current in entry transformer, phase C 
Table 2

\begin{tabular}{c|c}
\multicolumn{2}{c}{ THD for the entry transformer } \\
\hline Phase & THD (\%) \\
\hline A & 19.1 \\
\hline B & 18.3 \\
\hline C & 25.4 \\
\hline
\end{tabular}

By the observation of Figures 14 to 16, is verified that waves current format is similar to those one in medium voltage and the values as high as the values healthy THD found for medium voltage.

\section{Conclusions}

In this work was presented an experimental study of non-linear loads influence in medium voltage substations measurement transformers, more precisely in a voltage of 13,800 Volts.

It was used an experimental substation developed with this purpose, and tests were made with substation feeding a load configuration with predominance of devices like high pressure sodium lamps and weld electric machines.

The main obtained conclusion for analysis of presented results, it is that a considerable difference exists among values of THD-F for each component, measured in low voltage in that the load is feed, and values obtained in medium voltage side starting from substation measurement transformers secondary.

The first interpretation to be given is that, any diagnosis, correction measure or analysis in problems of Power Quality of an installation feed in medium voltage, cannot only be based on measurements done starting from measurement transformers.

It is known fact that a three-phase transformer with one of winding connected in delta, behaves as a natural filter for 3rd harmonic. In the case in subject, once the outlet windings of used transformer was feeding an unbalanced load, there was not this effect of filtering. Another point to be observed is that for measurements done in medium or high voltage, for 3 phases, the largest harmonic component was not 3rd, but 5th harmonic. This reinforces the statement done already that in any situation the deformation of current wave is larger in medium or high voltage than in low voltage.

With results here submitted, can declare firmly that exists mistakes introduction in harmonic components readings done starting from these transformers, mainly current transformer, as shown here.

The quantification of these mistakes should be object of futures studies. In the same way, can be object of future studies the evaluation of voltage wave deformation in a three-phases circuit feeding a balanced no-linear load.

Gratitude: The authors thanks collaboration of AREVA Company, and BANDEIRANTE ENERGIA, for availability of some equipments used in this work.

\section{References}

Bollen M, Math H. J. "Understanding Power Quality Problems". P.M.Anderson, Series Editor. IEEE press Editorial Board. 2000. NY USA;

Dranetz-BMI. "Power Quality Analysis". Dranetz - BMI Edison, 1991, NJ,USA;

Dranetz-BMI. "Handbook of Power Signatures". Dranetz-BMI Edison, 1997, NJ, USA ;

Maldonado Astorga O. A, R. Hiroshi Horii, L. O. M. Reis "Efficient Lamps in Public and Residential Illumination and their Effects on the Power Quality of the Secondary Voltage Distribution System". $8^{\circ}$. Congreso Luso - Espanhol de Engenharia Eletrotécnica. Algarve. Portugal. 2004-ISBN 972-8822-00-6;

Dias Guilherme A D. "Harmônicas em Sistemas Industriais". EDIPUCRS, 2a. Edição. Brasil,2002;

Meeting IEEE 519-1992 Harmonics Limits. IEEE Edit. USA;

Considerations for revising the IEC 61000-3-2 Harmonics Emissions Standard. 